\title{
Degree of effort and attitude change under forced-compliance
}

\author{
J. Miehael Blum and Jack M. Wright \\ UNIVERSITY OF FLORIDA
}

\begin{abstract}
Abstraet
Ss were tested on attitudes toward censorship before and one week after writing essays defending it. Those opposed to censorship (hence, playing a discrepant role) and above median perceived effort on the verbalization task became less opposed, whereas those below median effort "boomeranged." Also, perceived effort was shown to be relative to initial discrepancy.
\end{abstract}

\section{Problem}

In a study by King and Janis (1956) improvisation was found to be the mediating factor in opinion change resulting from playing a discrepant role. Ss improvising arguments in opposition to their own stand changed more toward the position advocated by the discrepant role than those reading a prepared speech. This finding, which suggests that attitude change after role playing is a function of the degree of effort expended in discrepant role enactment, is inconsistent with cognitive dissonance experiments on the effects of forced compliance. Dissonance studies by Cohen et al., (1958) and Rabbie et al., (1959) could find no significant relationship between quality of compliance and opinion change. However, the latter studies estimated the effort in compliance by the external criteria of judges' ratings of essay quality, and essay length. For a cognitive explanation of attitude change, it would appear more appropriate to measure Ss' perceptions of effort expended in writing the essays.

The present experiment tested the hypothesis that the degree of effort in discrepant role verbalization, as perceived by $\mathrm{S}$, relates to the degree of subsequent attitude change. Specifically, discrepant Ss who feel that they have performed with high effort should change more toward the position advocated by the essays than those perceiving low effort in their performance.

\section{Method}

Thirty-seven undergraduate students answered a Likert type questionnaire of 40 statements culled from various books on the topic of censorship of the arts. Results from a larger sample of 83 Ss showed this scale to have an odd-even reliability of .84 (corrected by the Spearman-Brown formula), which was deemed adequate for group comparisons. Ss were then given $20 \mathrm{~min}$. to write essays in defense of censorship. They were urged to make a clear and objective argument for censorship regardless of their own opinions. Immediately after the essays had been collected, Ss were asked to rate the degree of effort they had expended in writing the essays. This rating was made by marking six graphic rating scales describing their performance in terms of strength of effort, amount of concentration, number of significant points made, interest in the task, objectivity, and difficulty in undertaking the task. Scores in millimeters of position checked from the negative end of the scale for the six effort scales were summed to give a total effort rating. One week after the initial session the Ss who returned were administered the censorship questionnaire a second time.

The censorship questionnaire was scored so that higher scores indicated opposition to censorship. Change scores from first to second administration were computed as a proportion of total change possible in a negative direction (direction predicted by the hypothesis), so as to avoid any ceiling effect. Ss initially opposed to censorship were sorted into one of four discrepancy-effort combinations as follows. The median of the range of effort scores was employed as the cutting point between low and high effort participants. With the range of possible scores on the censorship questionnaire being from 40 to 200 and the objective midpoint being at 120 , the range from 126 to 134 of obtained scores was taken as moderately discrepant, while the range from 135 and up was taken as high discrepancy from the enacted role. By distributing the scores in this manner, it was possible to achieve equal cell entries in all four cells of the analysis $(\mathrm{N}=5$ per cell $)$.

\section{Results}

Table 1 shows the before and after mean opinion scores of Ss at two levels of initial opposition to censor-

Table 1. Pre- and Post-Verbalization Mean Opinion Scores for Two Levels of Opposition and Two Degrees of Verbalization Effort $(\mathrm{N}=20 ; 5$ per cell)

\begin{tabular}{lcccr} 
& \multicolumn{2}{c}{ Moderately Discrepant } & \multicolumn{2}{c}{ Highly Discrepant } \\
$\begin{array}{c}\text { Self rating } \\
\text { of effort }\end{array}$ & Pre & Post & Pre & Post \\
Low & 129.6 & 136.0 & 141.6 & 149.0 \\
High & 131.2 & 124.2 & 144.6 & 133.4
\end{tabular}


ship and in two categories of effort. An analysis of variance of the proportional pre-post change scores was performed. To preserve the direction of the proportional changes, positive values were added to and negative values were subtracted from unity. The main effect of effort was significant $(\mathrm{P}<.05)$ while discrepancy was not $(\mathrm{P}>.10)$. Interaction between opinion discrepancy and degree of effort proved to be statistically reliable $(\mathrm{P}<.05)$.

\section{Discussion}

The degree of effort with which a person approaches discrepant role playing has been shown to have a pronounced effect on the nature of his subsequent attitude position. In accord with this present finding, Zimbardo (1961) manipulated the effortfulness of the conditions under which Ss were required to read a prepared discrepant communication, and found that high-effort participants shifted more toward the discrepant stand than low-effort Ss. With the inclusion of the improvisation factor in the present study a very dramatic result was obtained. High-effort Ss shifted significantly toward the position which they had verbalized, while low-effort Ss became considerably more extreme in their initial positions. This boomerang effect has been discussed (Brehm \& Cohen, 1962) in dissonanse theoretical terms as a potential outcome in attitude change experiments, but has not been previously reported in the experimental forced compliance situation.

A further conclusion is derived from the significant interaction of effort and discrepancy. The effect of effort has been shown to be greater with high discrepancy than with moderate, suggesting that effort is perceived as greater or lesser relative to initial discrepancy. That is, it appears that a given "objective" level of effort is perceived as greater effort, perhaps by reason of stronger contradiction of own stand, when initial discrepancy is relatively large.

\section{Summary}

To investigate changes in attitudes as a result of effort expended in role playing, a censorship questionnaire was administered to $37 \mathrm{Ss}$ before and after writing an essay defending censorship of the arts. Ss also rated the degree of effort they had exerted in writing their essays. Ss were divided into four groups on the bases of being above or below the median on effort rating and being strongly or moderately opposed to censorship. Analysis of changes in attitudes of these four groups clearly supports the hypothesis that persons who see themselves as having expended more effort in contradicting their private stand change more toward the discrepant stand than those who perceive that they have expended less effort. Further, there was a definite boomerang effect for low-effort participants, such that they became more extreme in their original opposition. Finally, the data indicated that Ss judged their effort relative to the discrepancy between their own stand and that advocated by their essays.

\section{References}

BREHM, J. W., \& COHEN, A. R. Explorations in cognitive dissonance. New York: Wiley, 1962.

COHEN, A. R., BREHM, J. W., \& FLEMING, W. H. Attitude change and justification for compliance. J.abn. soc. Psychol., 1958, 56, 276-278.

KING, B. T., \& JANIS, I. L. Comparison of the effectiveness of improvised vs. non-improvised role-playing in producing opinion changes. Hum.Rel., 1956, 9, 177-186.

RABBIE, J. M., BREHM, J. W., \& COHEN, A. R. Verbalization and reactions to cognitive dissonance. J. Pers., 1959, 27, 407-417.

ZIMBARDO, P. G. Self-persuasion: improvisation or dissonance. Unpublished manuscript, New York University, 1961. Cited by J. W. Brehm and A. R. Cohen, Explorations in cognitive dissonance. New York: Wiley, 1962. P. 30. 